\title{
Overweight, obesity and chronic complications of diabetes mellitus in patients attending Diabetic Centre, Teaching Hospital, Jaffna, Sri Lanka
}

\author{
V Sujanitha, S Sivansuthan, P Selvakaran, R Parameshwaren \\ (Index words: Body mass index, obesity, chronic complications)
}

\begin{abstract}
Introduction To find out the association of Body Mass Index (BMI) with chronic complications of diabetes mellitus.
\end{abstract}

Methods A descriptive study was carried out on 8401 diabetic patients registered in the Diabetic Centre, Teaching Hospital of Jaffna, Sri Lanka from May 2009 to November 2013. BMI was categorised according to WHO Southeast Asia classification. Complications were identified from the summary sheets. Retinopathy was assessed with retinal images, peripheral neuropathy was assessed clinically with monofilament and biothesometer in selected patients. Nephropathy was assessed with urine microalbumin. Ischaemic heart disease, peripheral vascular disease and cerebrovascular accidents were assessed from medical records.

Results Of the 8401 patients $51.1 \%$ were males and $48.9 \%$ were females. The mean age of males was 61.49 years and females 60.42 years. The mean BMI was 23.70 $\mathrm{kg} / \mathrm{m}^{2}$. There was no significant difference in BMI according to gender. According to BMI $7.4 \%$ were underweight $\left(\mathrm{BMI}<18.5 \mathrm{~kg} / \mathrm{m}^{2}\right), 38.3 \%$ were normal weight, $20.5 \%$ were overweight and $33.8 \%$ were obese.

Rate of complications were ischaemic heart disease $21.1 \%$, cerebrovascular accidents $3.9 \%$, retinopathy $12.0 \%$, peripheral neuropathy $34.1 \%$ and nephropathy $39.5 \%$.

There was no significant difference in complication rates according to BMI categories except for hypertension.
Conclusion BMI was not associated with complications of diabetes. There was association between hypertension and BMI.

Ceylon Medical Journal 2015; 60: 94-96

\section{Introduction}

Overweight and obesity are becoming more prevalent in developing countries due to change in lifestyle [1]. One in five adults in Sri Lanka has either diabetes or prediabetes. Weight maintenance within the target body mass index (BMI) helps to prevent many diseases especially diabetes. The relationship between the metabolic control and development of chronic complications of diabetes is an important aspect of patient management [2].

It is known that the duration of diabetes mellitus, poor glycaemic control, hypertension, dyslipidaemia, smoking and BMI play a major role in development of macrovascular complications and microvascular complications $[3,4]$

This study examines the association between BMI and diabetic complications in patients who are treated at a diabetic centre of a Teaching Hospital in Sri Lanka.

\section{Methods}

A descriptive study was carried out at the Diabetic Centre, Teaching Hospital of Jaffna, Sri Lanka from May 2009 to November 2013. All patients followed up in the

Teaching Hospital, Jaffna, Sri Lanka.

Correspondence: VS, e-mail: <sujanitha@yahoo.com>. Received 18 February and revised version accepted 25 July 2015. 
unit were included in the study. Data were collected from summary sheets of each patients which were filled by medical officers of diabetic centre after detailed assessment. Of the 8707 registered diabetic patients, 306 summary sheets were not included due to incomplete data. A total of 8401 patients were included in the study.

BMI was categorized according to WHO South East Asia BMI classification [5,6]. The categories were underweight $\leq 18.5 \mathrm{~kg} / \mathrm{m}^{2}$; normal weight $=18.5-22.99 \mathrm{~kg} /$ $\mathrm{m}^{2}$; overweight $=23-24.99 \mathrm{~kg} / \mathrm{m}^{2}$; obesity $1=25-29.99 \mathrm{~kg} /$ $\mathrm{m}^{2}$; obesity $2 \geq 30 \mathrm{~kg} / \mathrm{m}^{2}$.

Weight was measured using a balance beam scale and height was measured using a wall mounted stadiometer without footwear and minimal clothes. Ischaemic heart disease (IHD) and symptomatic Cerebrovascular accidents (CVA) were identified based on medical records. Retinopathy was assessed using retinal images taken by retinal cameras. They were classified as follows: normal retina; maculopathy; background retinopathy; pre proliferative retinopathy and proliferative retinopathy. Peripheral neuropathy was identified by neurological examination and by using $10 \mathrm{~g}$ Semmes Weinstein monofilament on recommended sites on planter and dorsal aspects of feet and biothesometer in selected cases. The results were documented as peripheral neuropathy present or not present. Nephropathy was analysed based on urine micro albumin/urine creatinine ratio. Values less than $30 \mathrm{mg} / \mathrm{g}$ was categorised as normal, more than $30 \mathrm{mg} / \mathrm{g}$ was considered as nephropathy. Peripheral vascular disease (PVD) was identified based on clinical symptoms. Routine Doppler studies were not performed on patients.

Results were analysed using SPSS version 19.0. Unpaired $t$ test was used to determine differences in means between groups. Categorical data were evaluated by chisquared test. A two tailed $p<0.05$ was considered significant. The approval for the study was obtained from the Ethics Review Committee, Faculty of Medicine, University of Jaffna.

\section{Results}

The study population comprised of 8401 diagnosed diabetic patients of which $51.1 \%$ were males and $49.9 \%$ were females. The mean age of the study population was 60.97 years $(\mathrm{SD}=11.25)$. The mean $\mathrm{BMI}$ of the study population was $23.70 \mathrm{~kg} / \mathrm{m}^{2}\left(\mathrm{SD}=3.97 \mathrm{~kg} / \mathrm{m}^{2}\right)$. Mean BMI of males was $23.71 \mathrm{~kg} / \mathrm{m}^{2}$ and of females was $23.69 \mathrm{~kg} / \mathrm{m}^{2}$. There was no significant difference in BMI between males and females. Distribution according to BMI using WHO Southeast Asia classification was as follows: Underweight $\left(\mathrm{BMI}<18.5 \mathrm{~kg} / \mathrm{m}^{2}\right)$ 7.4\%, normal weight (BMI 18.5-22.99 $\mathrm{kg} / \mathrm{m}^{2}$ ) $38.3 \%$, over weight (BMI 23-24.99 kg/m²) 20.5\%, obesity 1 (BMI $\left.25-29.99 \mathrm{~kg} / \mathrm{m}^{2}\right) 27.5 \%$ and obesity 2 (BMI $>30 \mathrm{~kg} / \mathrm{m}^{2}$ ) $6.3 \%$ (Figure 1). IHD was present in $21.1 \%$ of diabetic patients and symptomatic CVA was present in $3.9 \%$. PVD was not analysed as patients were not assessed with routine duplex studies. Retinopathy was present in $12 \%$ of all diabetic patients, peripheral neuropathy in $34.1 \%$ and nephropathy in $39.5 \%$. The overall complication rate did not differ significantly in different BMI categories $(p>0.05)$.

Prevalence of hypertension was $42.2 \%$ in underweight, $52.8 \%$ in normal weight, $55.0 \%$ in overweight, $56.1 \%$ in obesity 1 and $65.2 \%$ in obesity 2 . The prevalence of hypertension increased with increasing BMI.

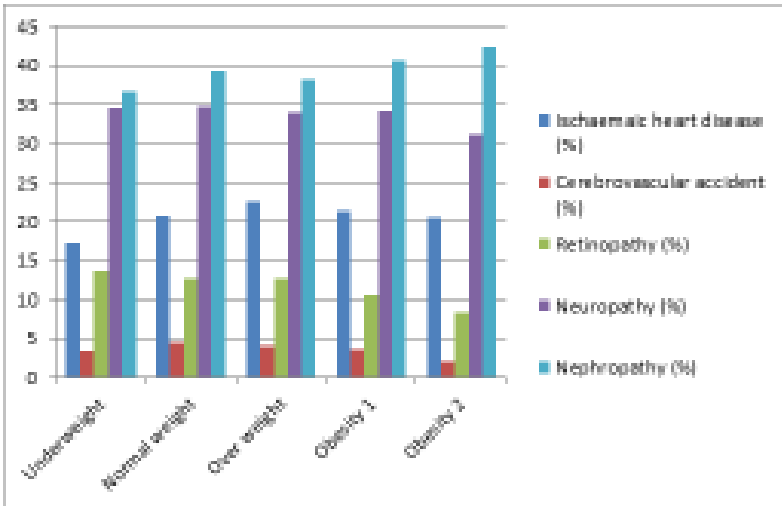

Figure 1. Percentage of diabetic complications according to BMI categories.

\section{Discussion}

Our study found that BMI is not an independent risk factor for developing diabetic complications. However high BMI is associated with increased incidence of hypertension.

The mean BMI of diabetic patients was $23.70 \mathrm{~kg} / \mathrm{m}^{2}$. There was no significant difference in BMI according to gender. This is similar to a study done previously in Sri Lanka which reported a mean BMI of $23.67 \mathrm{~kg} / \mathrm{m}^{2}(\mathrm{SD}=0.58)$ [9]. The average BMI is less than in the Western countries indicating that the South Asians are at risk of getting metabolic disorders at a lower BMI.

In this study $45.7 \%$ were underweight or normal weight and $54.3 \%$ were overweight or obese. This is similar to a study on the prevalence of overweight and obesity in Sri Lankan adults where the prevalence of overweight and obesity was $60.6 \%$ [10]. This difference could be due to life style modification after the treatment of diabetes. However the exact reasons needs to be studied further.

In this study increased BMI was not associated with any of the complications of diabetes. This is similar to findings of another study done in Sri Lanka which looked at association of chronic complications of type 2 DM [11]. They reported that increased BMI was not associated with any of the complications other than nephropathy [11]. Our study also showed increased prevalence of nephropathy with increasing BMI, however it was not statistically significant. 
Similar complication rates within different BMI categories may be due to good control of other risk factors such as hypertension, hyperlipidaemia and blood glucose. $\mathrm{BMI}$ itself is not an independent risk factor for developing complications of diabetes but it worsens hypertension, hyperlipidaemia and poor glycaemic control which in turn increase the chronic complications. There is evidence that high blood pressure is significantly associated with diabetic vascular complications [12]. In type 1 diabetic patients high BMI is associated with hypertension and atherogenic profile as part of insulin resistance syndrome [13]. In our study the prevalence of hypertension increased with BMI, however the overall macro and microvascular complication rates were not associated with BMI.

Many studies have shown that overweight and obesity are associated with increased risk of complications $[14,15,16]$. This is through the worsening of glycaemic control and blood pressure. To prevent the complications and achieve the ideal target, patients need either higher dosage of medications or more number of medications.

\section{Acknowledgements}

The authors thank the staff of Diabetic Centre, Teaching Hospital, Jaffna, Sri Lanka for the support given in data collection and analysis.

\section{Conflicts of interest}

There are no conflicts of interest.

\section{References}

1. Frank BH. Globalization of Diabetes. The role of diet, life style and genes. Diabetes Care 2011; 34: 1249-57.

2. Katulanda P, Wijesuriya M, Constantine GR, et al. Prevalence and projections of diabetes and pre-diabetes in adults in Srilanka (SLDCS). Diabetes Med 2008; 25: 1062-9.

3. Martín-Timón I, Sevillano-Collantes C, Segura-Galindo A, Cañizo-Gómez FJ. Type 2 Diabetes and cardiovascular disease: Have all risk factors the same strength? World $J$ Diabetes 2014; 5: 444-70.

4. Stratton IM, Adler AI, Neil HAW, et al. Association of glycaemia with macrovascular and microvascular complication of type 2 diabetes (UKPDS 35). BMJ 2000; 321: $405-12$

5. Anurad E, Shiwaku K, Nogi A, et al. The new BMI criteria for Asians by the regional office for the Western Pacific region of WHO are suitable for screening of overweight to prevent metabolic syndrome in elder Japanese workers. $J$ Occup Health 2003; 45: 335-43.

6. WHO Expert Consultation. Appropriate body mass index for Asian populations and its implications for policy and intervention strategies. Lancet 2004; 363: 157-63.

7. Agarwal RP, Ranka M, Beniwal R, et al. Prevalence of micro and macrovascular complications in type 2 diabetes and their risk factors. Int J Diab Dev Countries 2004; 24 : 11-16.

8. Zaheer AK, Muhammad AS, Rooh AM. Prevalence and risk factors of diabetes in adult population of South Asia. Clinical Med Diagnostics 2013; 3: 18-28.

9. Hettihewa LM, GunasekeraSW, Jayasinghe SS, et al. Lipid abnormalities in type 2 diabetes mellitus patients in Srilanka. Galle Med J 2007; 12: 1-4.

10. Katulanda P, Jayawardena MA, Sheriff MH, et al. Prevalence of overweight and obesity in Srilankan adults. Obes Rev 2010; 11: 751-2.

11. Wijesuriya MA, De-Abrew WK, Weerathunga AL. Association of chronic complications of type 2 diabetes with the biochemical and physical estimations in subjects attending single visit screening for complications. J Diabetol 2012; 1: 3

12. Ramachandran A, Snehalatha C, Satyavani K, et al. Prevalence of vascular complications and their risk factors in type 2 diabetes. J Assoc Physicians India 1999; 47: 1152-56.

13. Purnell JQ, Hokanson JE, Marcovina SM, et al. Effect of excessive weight gain with intensive therapy of type 1 diabetes on lipid levels and blood pressure, results from DCCT. JAMA 1998; 280: 140-46.

14. Weerasuriya N, Siribaddana S, Dissanayake A. Long term complications in newly diagnosed Srilankan patients with type 2 diabetes. Q J Med 1998; 91: 439-43.

15. Christophe EM, Ivo HL, Luc FV. Impact of overweight on chronic microvascular complications in type 1 diabetic patients. Diabetes Care 2005; 28: 1649-55.

16. Litwak L, Goh SY, Hussein Z, et al. Prevalence of diabetes complications in people with type 2 diabetes mellitus and its association with baseline characteristics in the multinational A1 chieve study. Diabetol Metab Syndr 2013; 1: 57. 